\title{
The Waves of Containerization: Shifts in Global Maritime Transportation
}

\author{
David Guerrero \\ French Institute of Science and Technology for Transport, Development and Networks (IFSTTAR), Universite de Paris-Est, France. E-mail: \\ david.guerгero回ifsttar.fr \\ Jean-Paul Rodrigue \\ Dept. of Glabal Studies \& Geagraphy, Hofstra University, Hempstead, New York, United States. E-mail: jean-paul.rodrigue回hafstra.edu
}

\begin{abstract}
This paper provides evidence of the cyclic behavior of containerization through an analysis of long, medium and short waves of container ports. The container, like any technical innovation, has a market and diffusion potential where a phase of maturity is eventually reached. Evidence from the global container port system suggests five successive major long waves of containerization with a shift of the momentum from advanced economies to developing economies, but also within developed and developing economies. While long, medium and short wave patterns have been clearly identified within the global container port system, these waves are simply illustrative of major macroeconomic, technological and sometimes political shifts within the global economy. They do not explain the causes, but simply the consequences in the distribution in traffic and growth (or decline). Yet, they provide strong evidence that containerization has a cyclic behavior illustrative of economic processes and that inflection points are eventually reached, marking the end of the diffusion of containerization in a specific port or port range. Future expectations about the growth of containerization thus need to be assessed within an economic cycle perspective instead of the rather linear perspectives in which containerization is generally considered.
\end{abstract}

Keywords: Maritime transportation, Ports, Containerization, Economic cycles.

\section{INTRODUCTIIN: THE SPATIAL AND FUNCTIINAL DIFFUSION DF THE CDNTAINER}

After more than half a century since its introduction, the container continues its spatial and functional diffusion within global transport systems. Such diffusion is far from being uniform in time and space, on par with the changes in the commercial geography of the global economy. This is particularly the case relative to the export-oriented strategies of Asian countries that have rebalanced a global trade system used to focus around the economic triad (North America, Europe, Japan). In light of these economic and technological changes, economic cycles are offering a perspective to investigate the spatiotemporal evolution of containerization. A cycle is a synthetic representation of a relatively complete evolution of a system, from its introduction to its potential obsolescence. A wave is a specific moment - a phase - within a cycle where specific market and technological conditions apply which is associated with a specific growth momentum. Changes are usually measured through growth rates since different waves have different momentum. Both a cycle and its waves can be 
applied to an individual port, a port range, or to the whole global port system. For an individual port, a cycle represents the full realization of its hinterland (gateway) and foreland (hub) potential in light of geographical and site characteristics. For a port range, a cycle relates to the setting and interrelations of its ports to service its commercial hinterland, implying a rank/size outcome in the port structure with a few major gateways dominating. At the global level, a cycle would be the complete diffusion of containerization within the port system, a process which is obviously incomplete and characterized by different levels of maturity.

The paper will look at economic cycles as components of the derived demand of containerized maritime transport over the long, medium and short terms, and this mainly at the global level. Within each of these temporal frameworks the paper will analyze spatial patterns that can be statistically evidenced. Each type of cycle requires the usage of a specific methodology. Long waves within cycles (evolution since the beginning of containerization) will be looked at through cluster analysis where a large sample of container ports is categorized according to their growth pattern, namely its time frame and scale. Medium wave within cycles, using shiftshare analysis, will focus on the 2000s decade, one that has seen fundamental changes in the structure of global shipping networks with the rapid rise of new ports, namely in China, but also of transshipment hubs. This period has also seen since 2008 the most significant paradigm shift since the beginning of containerization with a significant and unanticipated drop in traffic among the bulk of the world's major container ports, particularly in Europe and North America. Shift-share analysis will particularly look at inflection points indicative of a transition within a wave. For short wave cycles the usage of technical analysis tools will look at characteristics such as amplitude as well as divergences (trend break). Because of the data requirements (monthly container throughput), short waves can only be applied to a limited sample of ports.

\section{GLOBAL SHIFTS IN PRODULTION AND TRANSPORTATIIN}

\section{The Dynamics of Containerization}

Containerization has been the most dynamic physical component of globalization, far exceeding the growth of the value of exports and the GDP (Figure 1). As globalization developed, each new individual, GDP or export unit was associated with a higher level of container flows. While up to 1980 the growth of container port throughput went on par with the growth of the value of exports, a divergence is noted afterwards. Containerization entered the acceleration phase of its diffusion cycle as a fundamental support of export oriented strategies pursued by Asian economies. Therefore, an array of growth factors is at play to explain the substantial growth of containerization and more interestingly the contribution of these factors in time varies. While additional traffic resulting from organic growth is the most salient factor, imbalanced trade flows (empty containers) and the configuration of shipping networks relying on transshipment hubs (double counting of containers) have also contributed to additional containerized flows and port handlings. As economies of scale were applied to maritime shipping transshipment became more salient. The quantity of containers being transshipped increased from around 11\% of all cargo handled by container ports in 1980 to about $30 \%$ in 2010, which is also a notable factor in the growth of containerized traffic. 


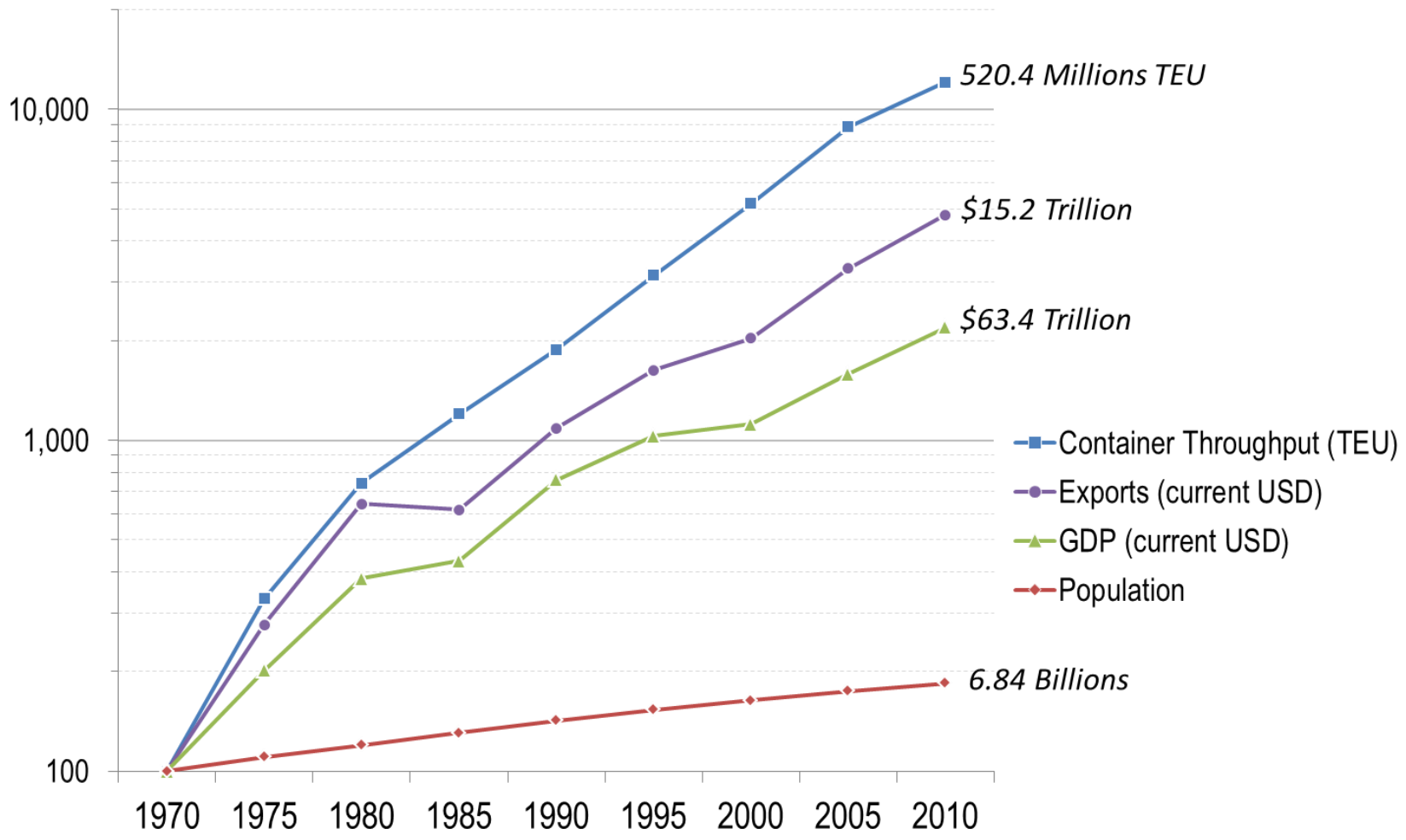

Figure 1: Global Trade and Container Throughput (1970=100)

Also, Figure 1 brings forward questions about the additional growth and diffusion potential of containerization in light of the finiteness of globalization, of receding economic opportunities (production and consumption) and the expected demographic shifts, namely the stabilization of the global population within two decades as well as its ongoing aging. For instance, if container throughput was to double from the 520 million TEU figures observed circa 2010 to 1 billion TEU, this begs to wonder the level of related consumption and the physical capacity of transport infrastructures to handle such a level of material flows. Obviously, this question cannot be readily answered, but a cycle perspectives underlines that maturity will eventually be achieved for global containerized freight distribution and that close attention must be paid to identify inflection points. The point is that future expectations about the growth of containerization need to be assessed within an economic cycle perspective instead of the rather linear perspectives in which containerization is generally considered.

\section{Shifts in Traffic Concentration}

The use of concentration measures, particularly the Gini coefficient, is prevalent in port studies, even if the coefficient is a technical measure that does not reveal the processes behind the changes in the level of concentration (Notteboom, 2006). Based from a sample of ports derived from Containerization International and having a traffic of more than 150,000 TEU in 2010, the number of container ports grew from 57 in 1970 to 317 in 2010 (Figure 2). Compared to the exponential growth in traffic the number of ports follows a logistic curve (Sshaped) as it increases rapidly in the late 1970s and then slows in the 2000s. The number of ports appears to be a leading indicator for the growth of containerized traffic and the recent 
stabilization in the number of container ports may be indicative of a forthcoming stabilization of containerized traffic.

The concentration of cargo has also considerably changed between 1970 and 2010. The Gini coefficient reveals two distinct phases. The first (1970-1990) is characterized by an uninterrupted trend of concentration of container throughput (from 0.57 to 0.70 ) with the emergence of mega hubs (e.g. Hong Kong, Singapore, Rotterdam, Hamburg). The second (1990-2010) is characterized by a reversal of the trend with initially a small dispersion (from 0.70 to $0.69,1990-1995$ ) as Chinese container ports were brought online. From 1995 the Gini coefficient remained stable, in part because of the setting of new transshipment hubs and the ongoing growth of Chinese ports.
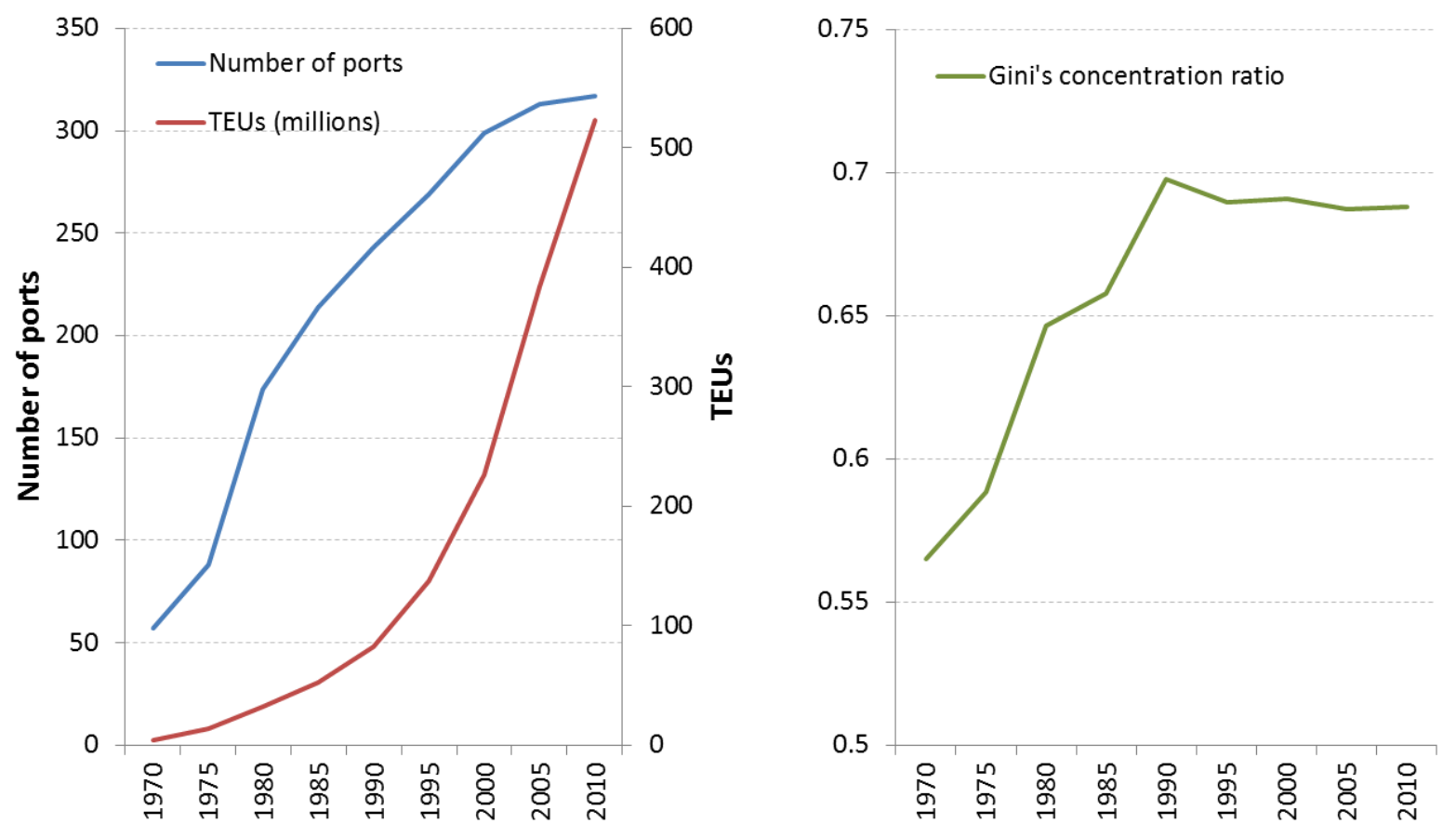

Figure 2 : Concentration of the Global Container Port System, 1970-2010

The trend of concentration from the 1970s to the 1990s is particularly evident at the top of the container port hierarchy (Figure 3). In $19707 \%$ of all ports $(n=4)$ were handling $25 \%$ of the total container throughput. In 1995 , only $1 \%$ of all ports $(n=4)$ were handling the same traffic share while $7 \%$ of all ports $(n=28)$ where handling $50 \%$ of the throughput. Since 1995 , the trend, as evidenced by the Gini coefficient, has stabilized with around $21 \%$ of all ports handling $75 \%$ of the global throughput. Thus, in the fifteen years after 1995 there has been little change in the level of concentration, underlining that global container port system relies since then on different dynamics than concentration since the main hubs have already been established. 


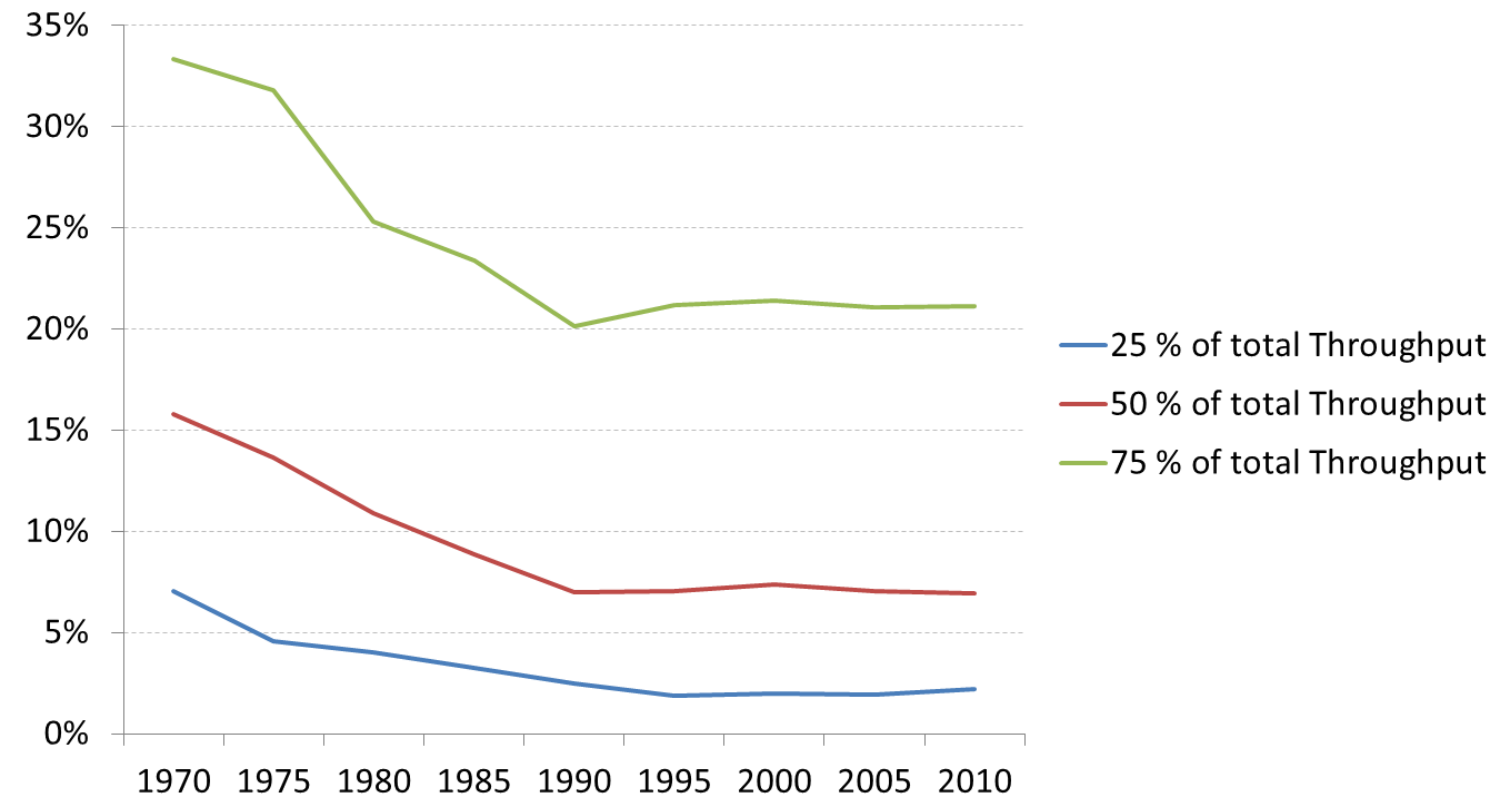

Figure 3 : Percentage of Ports Needed to Handle 25\%, 50\% and 75\% of Total Container Throughput, 1970-2010

\section{Long, Medium and Shart Transpartation Waves}

Cycles are amply covered in the business and economic literature, an investigation that can be traced back to the seminal work of Kondratieff (1935) who was suggesting that economic cycles usually imply a time frame of 45 to 60 years. A significant branch of investigation in economics also concerns product life cycles and the related shifts in production as a product reaches a phase of maturity (e.g. Hayes and Wheelwright, 1979). The conceptual usage of cycles within maritime and port studies is much more limited, but implicitly implied in port development models (e.g. Bird, 1963; Hayuth, 1981) and in particular for the literature addressing the diffusion of containerization (e.g. Levinson, 2006; Notteboom and Rodrigue, 2009; Rodrigue, Comtois and Slack, 1997). Yet, these approaches consider containerization as a whole and have not looked at what cycles and their waves imply at the individual port level and the fact that different ports have been part of different growth patterns and thus part of different economic cycles. While studies looking at the dynamics of individual port or port range are common, global investigations appear much less prevalent (e.g. Fremont, 2007; O'Connor, 2010; Ducruet and Zaidi, 2012). One reason that can be advocated for this shortcoming is that such an approach requires familiarity with global macroeconomic processes and international trade, areas where port studies have conventionally not placed much focus.

To better capture the temporal and spatial dynamics of containerization, cycles will be looked over long (decades), medium (years) and short (months) waves (Figure 4). 

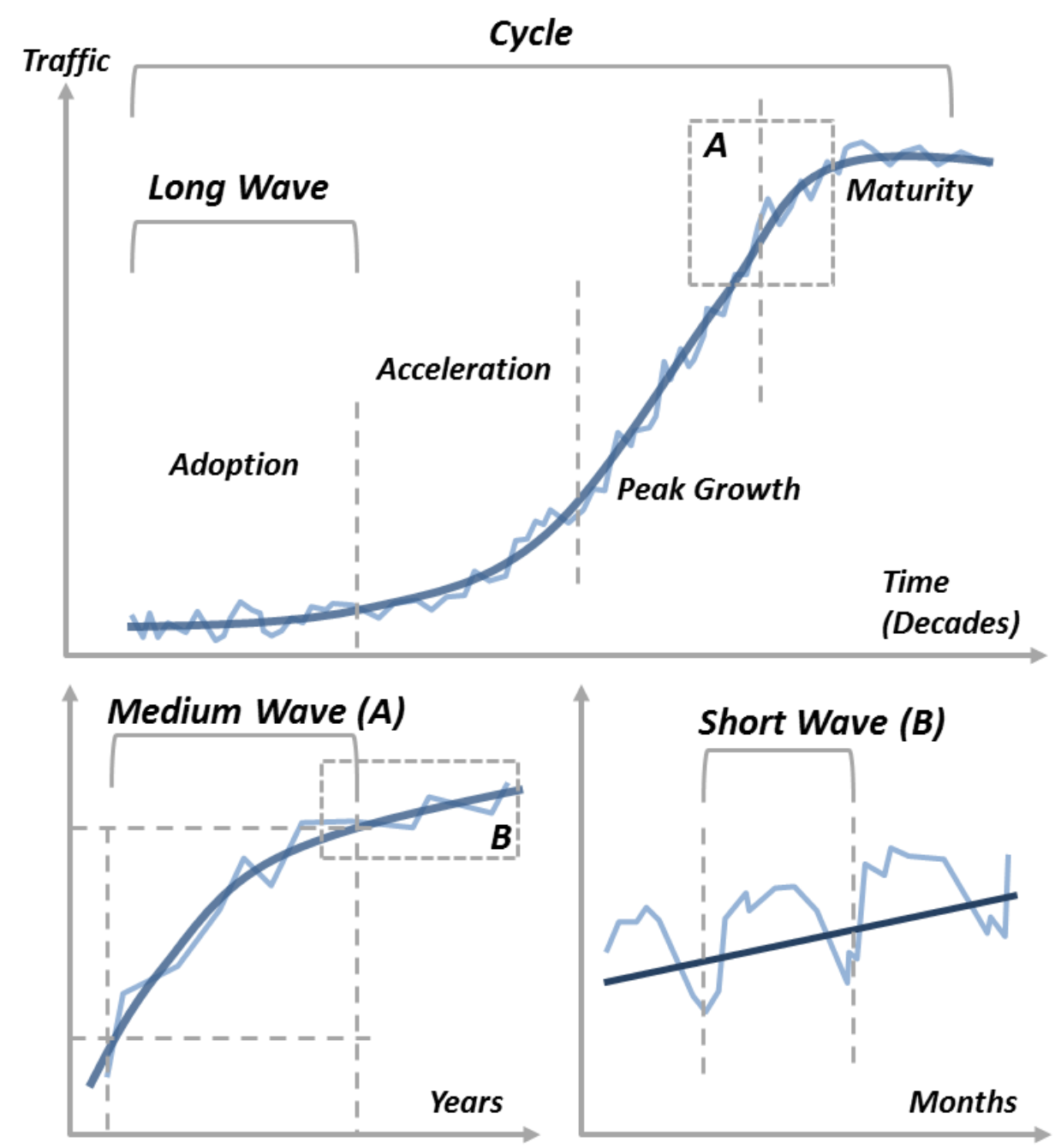

Figure 4 : Long, Medium and Short Waves of Containerization

Long waves typically investigate the sequential stages involving the realization of a cycle, let it be at the port or the global levels within a time frame that usually spans a decade. At the global level, four long waves appear to be typical to the development of containerization (as reflected on Figure 1). During the adoption wave of the early 1960s, containerization was yet an unproven technology with a few competing standards in terms of sizes and latching systems. The services offered were specific (point to point), mostly using converted cargo ships. Still, containerization demonstrated that it was achieving productivity gains since it involved a much more efficient form of port operations. During the early 1970s, containerization entered its acceleration wave and was recognized as a promising mean of transportation. New services and consequently new networks were being established, which multiplied its productivity, with growing volumes and the beginning of the application of economies of scale, both for modes and terminals. In the 1980s, pendulum services, which would become the standard network configuration for containerized maritime shipping, were being set across maritime ranges, particularly the Atlantic (Slack, 1999).

By the 1990s, containerization became the dominant support of global trade and entered its peak growth wave. Its diffusion was massive, particularly in newly industrializing economies 
such as China. Network development was facing growing complexities, which led to the setting of major transshipment hubs reconciling regional and global shipping networks. As economic cycles theory underlines, systems eventually reach a phase of maturity where growth is much less related to diffusion but with standard economic changes and the exploitation of remaining niches, both functional (e.g. the containerization of commodities) and locational (e.g. a new transshipment hub at a low deviation location). It remains uncertain to what extent this phase may have already been achieved in some parts of the world. For instance, the maturity of containerization in Japan is salient and may also been emerging in parts of North America and Europe. Yet, in regions such as Latin America, South Asia and the Middle East, containerization has still substantial potential for growth.

A medium wave considers the changes taking place within a long wave where the system is undertaking a paradigm shift from one long wave to another; a point of inflection. This mostly relates to changes taking place over a few years. For instance, during a medium wave a port may shift from peak growth to maturity due to changing market conditions, such as demand saturation in its hinterland. Medium waves are therefore particularly useful at identifying the time frame and the conditions associated with this shift. Otherwise, a medium wave perspective may simply underline that growth conditions and patterns have not changed during the time frame considered and thus that a port remains within its existing long wave.

Short wave maritime cycles consider the fluctuations of monthly port traffic and may underline a dynamic that is irrespective of long and medium waves. Several ports have a traffic that is relatively stable on an annual basis, while others will experience periods of peak and low activity. The frequency and amplitude of short-wave maritime cycles can be linked to its size, function (gateway or transshipment hub) and the nature of its hinterland. Transshipment hubs tend to have short wave cycles that have low volatility since they consolidate and compound the traffic of several hinterlands. Gateway ports servicing a single commercial hinterland will tend to have traffic fluctuations related to retail activities, which tend to peak around October and reach a low point around February.

\section{LDNG WAVES OF CDNTAINERIZATIIDN}

\section{Identifying Long Waves}

Hierarchical Cluster Analysis (HCA) is a statistical method commonly used for finding relatively homogeneous clusters of observations based on their measured attributes. From a dataset, HCA finds groups (clusters) that minimize their endogenous dissimilarity according to a set number of groups. Initially it places each observation in a separate cluster and then combines the clusters sequentially, reducing the number of clusters at each step until only one cluster is left. When there are N cases, this involves N-1 clustering steps. This hierarchical clustering process can be represented as a dendrogram where each step in the clustering process is illustrated by a join of the tree until only one branch is reached. It is for the analyst to decide of the relevant number of groups, but such a choice is made in light to have the minimum number of group possible with an acceptable level of dissimilarity. The Ward clustering procedure takes into account the chi-square distances between the profiles and the associated observations (Everitt, Landau and Leese, 2001). This way it provides a 
decomposition of inertia with respect to the nodes of a dendrogram. The total dissimilarity of the dataset is reduced by a minimum at each successive level of merging the observations.

HCA allows identifying homogeneous clusters of ports based on the evolution of their share of global container throughput between 1970 and 2010 in five year increments. Through a review of the literature, it came as a surprise that this methodology appears to have seen limited application to the analysis of cycles (Kuczynski, 1980) and even fewer applications to port studies could be identified. For instance, it has mainly been used to classify ports by their function and performance level (e.g. Tongzon, 1995).

The data for the analysis was taken from Containerization International (CI) figures and retained over five year increments that include nine periods from 1970 up to 2010. The main selection criteria was that the port should have exceeded a traffic of 150,000 TEU for a year in the time sequence and that data was available for 2010. In total 323 container ports were retained for the analysis. However, there were 61 missing observations from the CI database out of a total of 2907 ( 323 ports $x 9$ time periods), the majority of them for ports of less than 500,000 TEU. For these missing observations a linear interpolation was performed from data available for adjacent years (e.g. calculating missing traffic data for 1985 using available data for 1984 and 1986). This enabled to keep 61 ports in the sample by inferring traffic with a good level of confidence. If there was more than one missing data in the time sequence, then the port was discarded.

The comparative size of ports requires caution as several ports can be considered more statistical agglomerations than functional entities. For instance, the port of Shenzhen in the Pearl River Delta is composed of several large port facilities (e.g. Yantian, Chiwan, Shekou) that act as distinct operational entities and each port often servicing different hinterlands. The same observation applies to Guangzhou and Shanghai that are multiport (terminal) entities. The agglomeration effect may hide different dynamics and even membership to different waves, but because the data is collected at the port authority level, these nuances cannot be identified and analyzed here.

Applying the HCA methodology to the container port dataset resulted in the selection of 7 classes where each component has a similar temporal and growth behavior (Figure 5). Adding additional classes, such as going from 7 to 8 classes, does not drop the level of dissimilarity in a significant manner, while using less than 5 classes substantially increased dissimilarity. While 7 classes appear optimal, the dendrogram underlines their respective distinctiveness and the relevance of using sub-classes in two cases. Therefore, instead of having 7 waves (A to G), 5 waves can be identified (A to E) with two waves having phases (B.1 and B.2 as well as D.1 and D.2). The earlier the class branches out on the dendrogram, the more the class is distinct and cohesive. 
Dissimilarity per number of classes

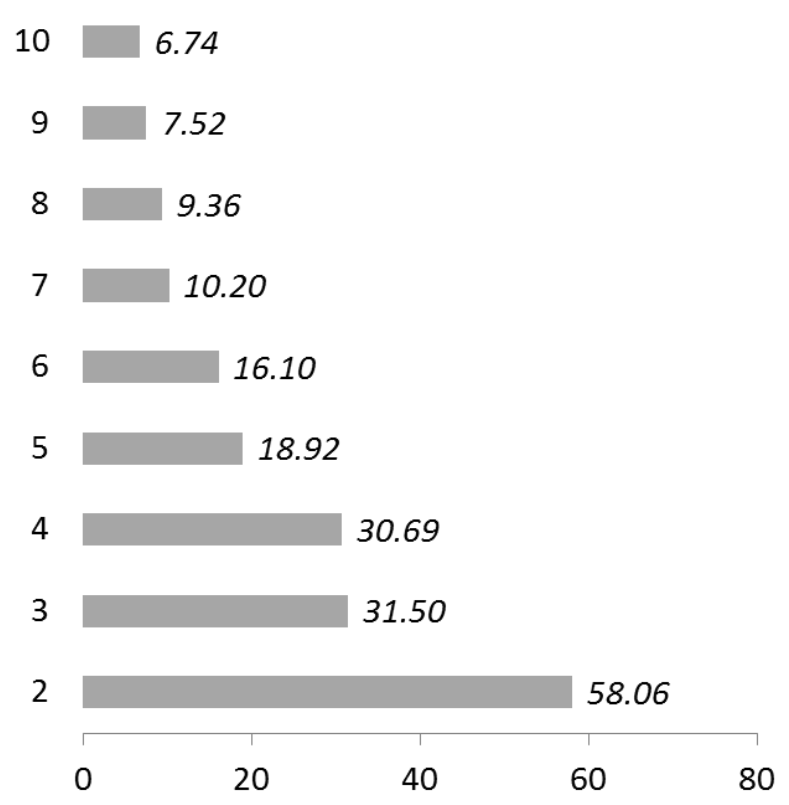

Dissimilarity dendrogram for 7 classes

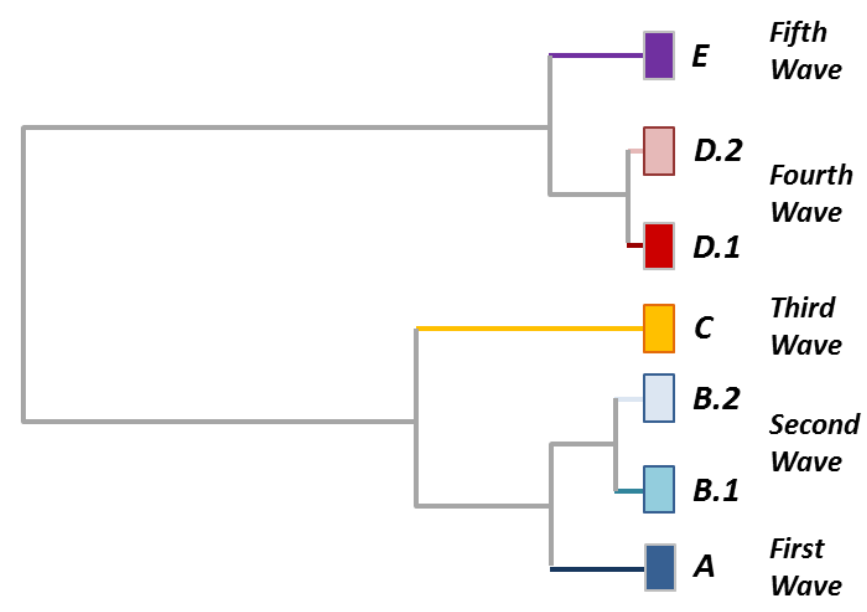

High Dissimilarity Level Low

Figure 5 : Hierarchical Cluster Analysis Parameters of Global Container Ports, 1970-2010

\section{The Five Long Waves of Containerization}

By using HCA, the evolution of the global container port system can be divided into seven classes representing five long waves (Figure 6). Each wave represents a specific temporal growth pattern of containerization. It is worth underlining that the inclusion of a port to a specific class does not imply that the port was not handling container traffic in prior periods, but that traffic growth became significant from the wave the port belongs to. While at the aggregate level the growth of container traffic is exponential, each class depicts a different growth dynamic reflecting their specific development. 

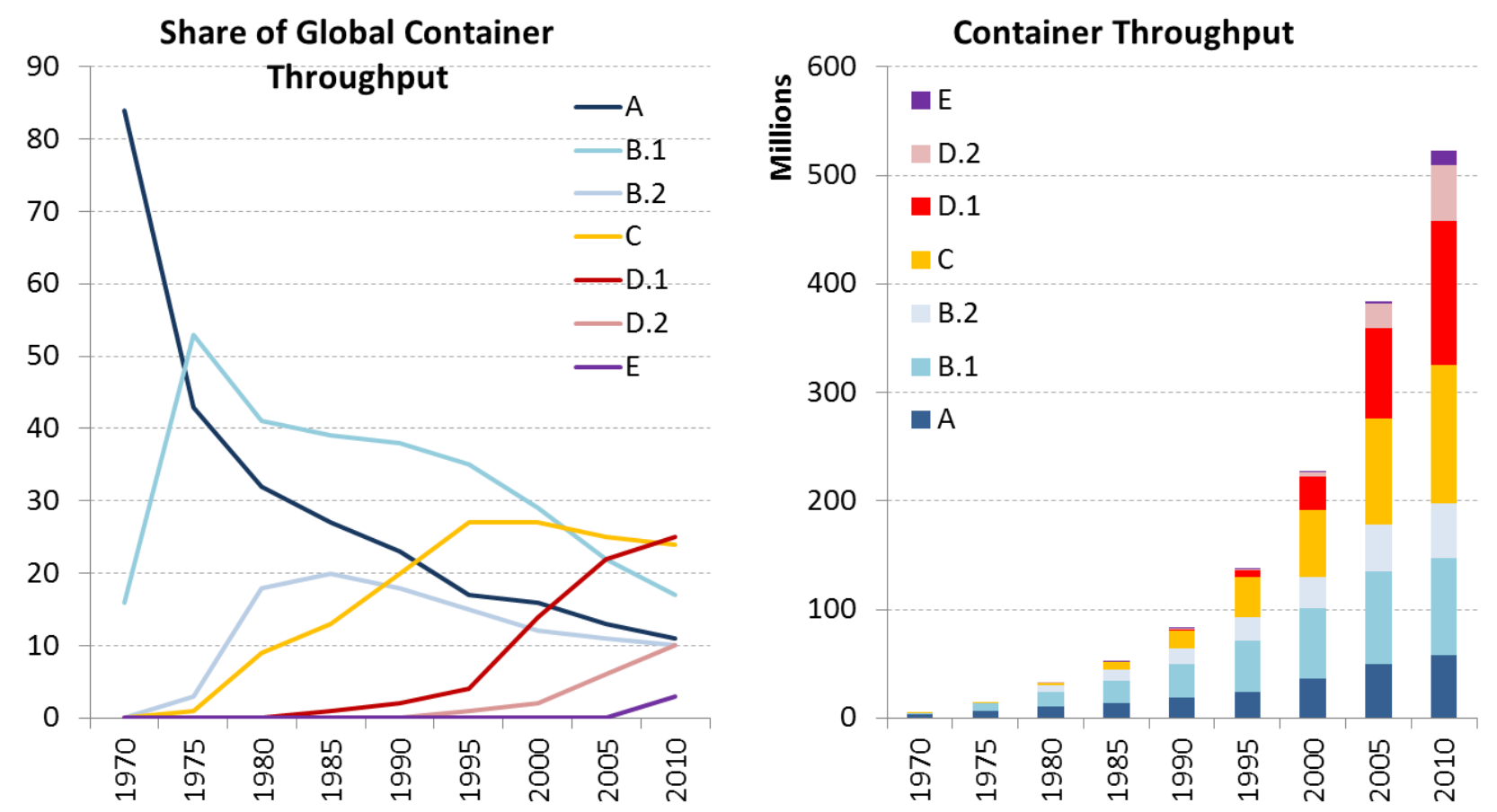

Figure 6 : Evolution of Absolute and Relative Container Throughput by Hierarchical Cluster Analysis Class, 1970-2010

Figures 7 to 11 each depict the global container traffic at a representative year of the seven waves (each decade from 1970 to 2010). It is important to underline that the classification range of each wave is different to better depict the relative importance of container ports at specific points in time. Approximately, the reference scale doubles for each wave.

First wave (A); the pioneers of the triad (Figure 7). The first containerized services were established by Sea-Land in the late 1950s and early 1960s. By the 1970s, regular transatlantic (Northern range of Western Europe and American East Coast) and transpacific services (Japan / Australia and American West Coast) were established through ports that were the firsts to adopt containerization and are thus considered to be the pioneers (e.g. New York, Yokohama, Oakland and Hamburg). They are almost all part of the economic triad which leaded globalization; North America, Western Europe, Japan and Australia. These ports accounted for the dominant share (about 80\%) of the global throughput in 1970, but this share fell rapidly afterwards. Few of these ports kept their primacy, which is in part explained by the fact that the rationale behind their emergence played to a much lesser extent or that limited room was available for terminal expansion. A port site could be suitable to a specific volume, but once this volume has been reached, there may limited opportunities for port expansion. For instance, the initial primacy of Oakland was overtaken by the ports of Los Angeles / Long Beach covering a wider regional market and having more room for expansion and better inland connections. The exception is Australia where Sydney and Brisbane remained dominant gateways. The first wave underlines that several pioneers were able to initially capture the opportunities of containerization, but due to market or technical reasons, were unable to keep this initial advantage for internal (technical) reasons but also for factors completely outside their control such as a shift in trade patterns. 


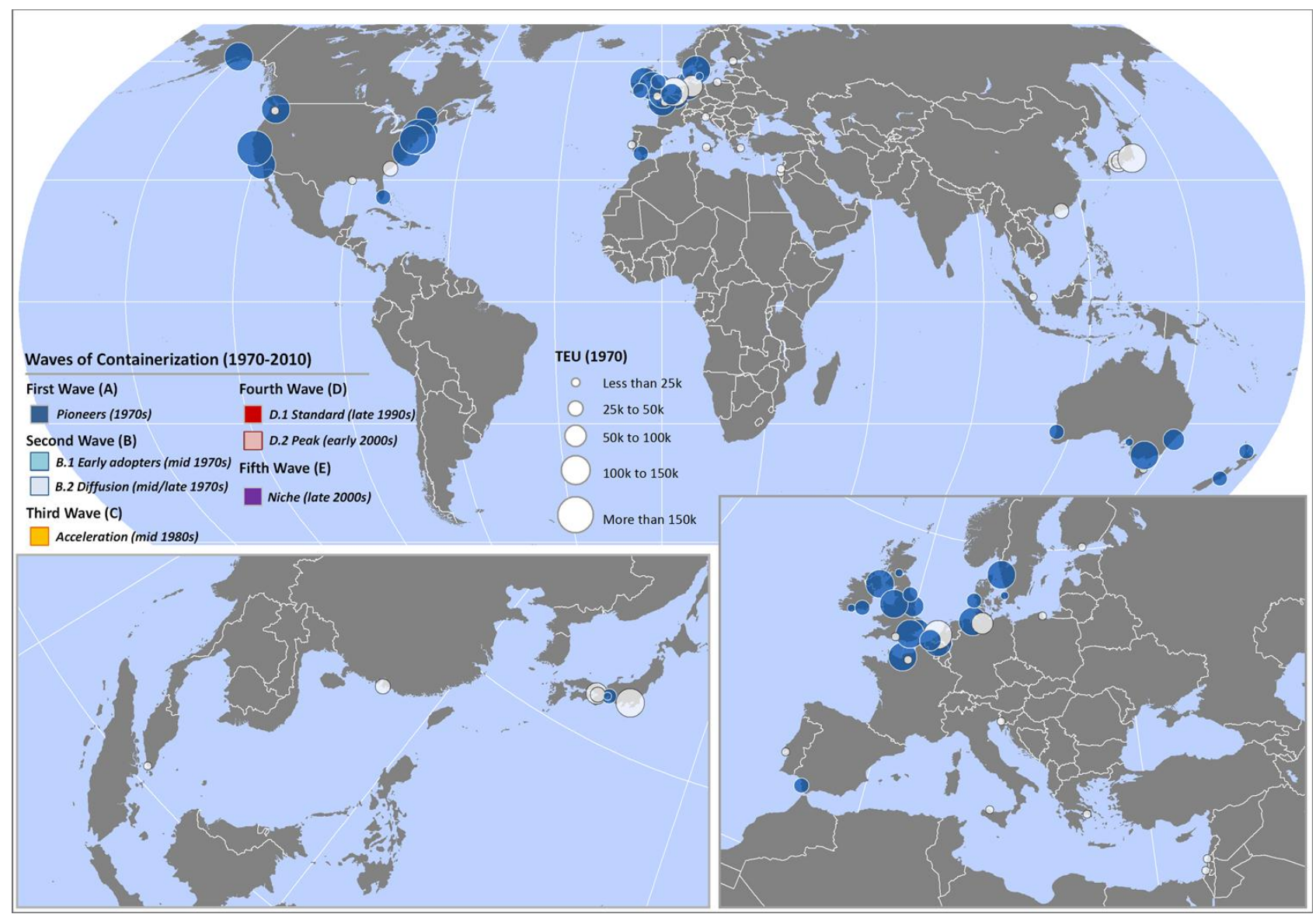

Figure 7 : The First Wave of Containerization, 1970 - The Pioneers of the Triad

Second wave (B); adoption in the triad and its periphery (Figure 8). This wave represents an expansion of containerization within the triad as well as with its regional trade partners. It takes place in two phases with the first (B.1) occurring in the mid-1970s and accounting for a larger share of the world's throughput. While many of these ports were operational in the early 1970s, their market share increased and several became the world's dominant container ports, until overtaken by Chinese ports in the 2000s. This shift took place not because of a lack of growth for wave B.1 ports, but because of differential growth rates characterizing ports going through different waves. Salient examples include Rotterdam, Tokyo and Hong Kong. Wave B.2 began in the late 1970s and mostly took place in ports adjacent to the triad, such as in the Caribbean, Latin America, the Mediterranean and among emerging East Asian tigers (Thailand, Taiwan and Hong Kong). From a pattern dominated by the triad, containerization undertook the initial phase of its global diffusion by embedding itself in commercial relations through a substitution effect of conventional break bulk trades. More intermediary locations in the Middle East and India were also involved since the growth of containerized shipping between Asia and Europe presented opportunities to add port calls along pendulum routes. Figure 8 clearly underlines the extent to which this wave (and the first wave as well) is dominantly bound to the dynamics spearheaded by North America, Western Europe and Japan. 


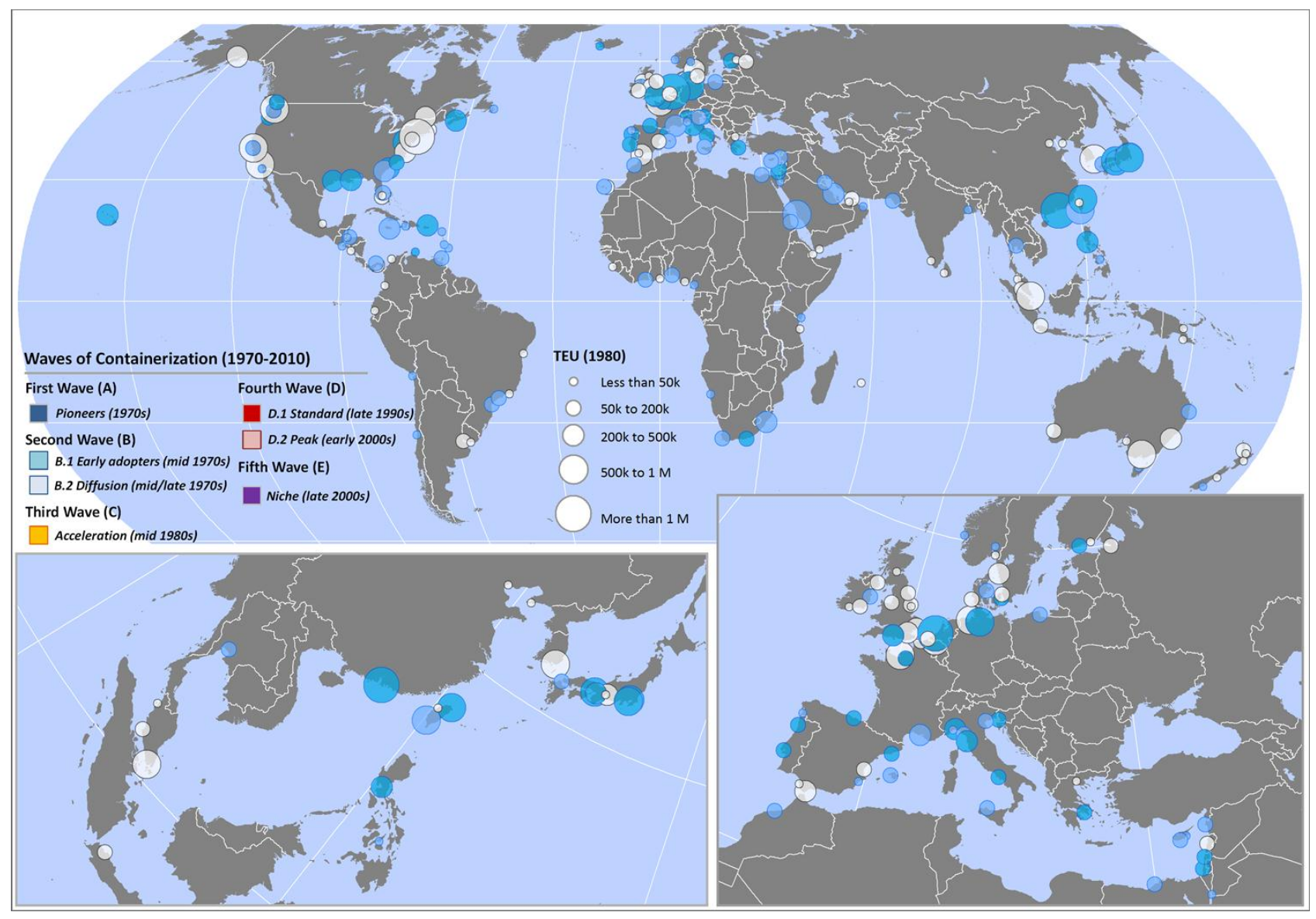

Figure 8 : The Second Wave of Containerization, 1980 - Adoption in the Triad and its Periphery

Third wave (C); global diffusion (Figure 9). Concerns the largest number of ports and namely captures the massive diffusion of containerization, particularly the incorporation of East and Southeast Asia (without China) in global trade relations through the beginning of offshoring as well as the emergence of early transshipment hubs. From the mid/late 1980s the emergence of a new function in containerized maritime shipping is noted; transshipment. As the number of container ports increased the network strategy to serve them favored a shift from point-topoint services along pendulum routes to the usage of hubs-and-spoke services. Indeed, several ports that emerged during this wave became major transshipment hubs through their intermediary locations along major shipping corridors such as Singapore, Colombo, Dubai, and Algeciras. This wave is statistically the most distinctive since the growth takes place in a similar time frame (mid-1990s) and at a similar level. 


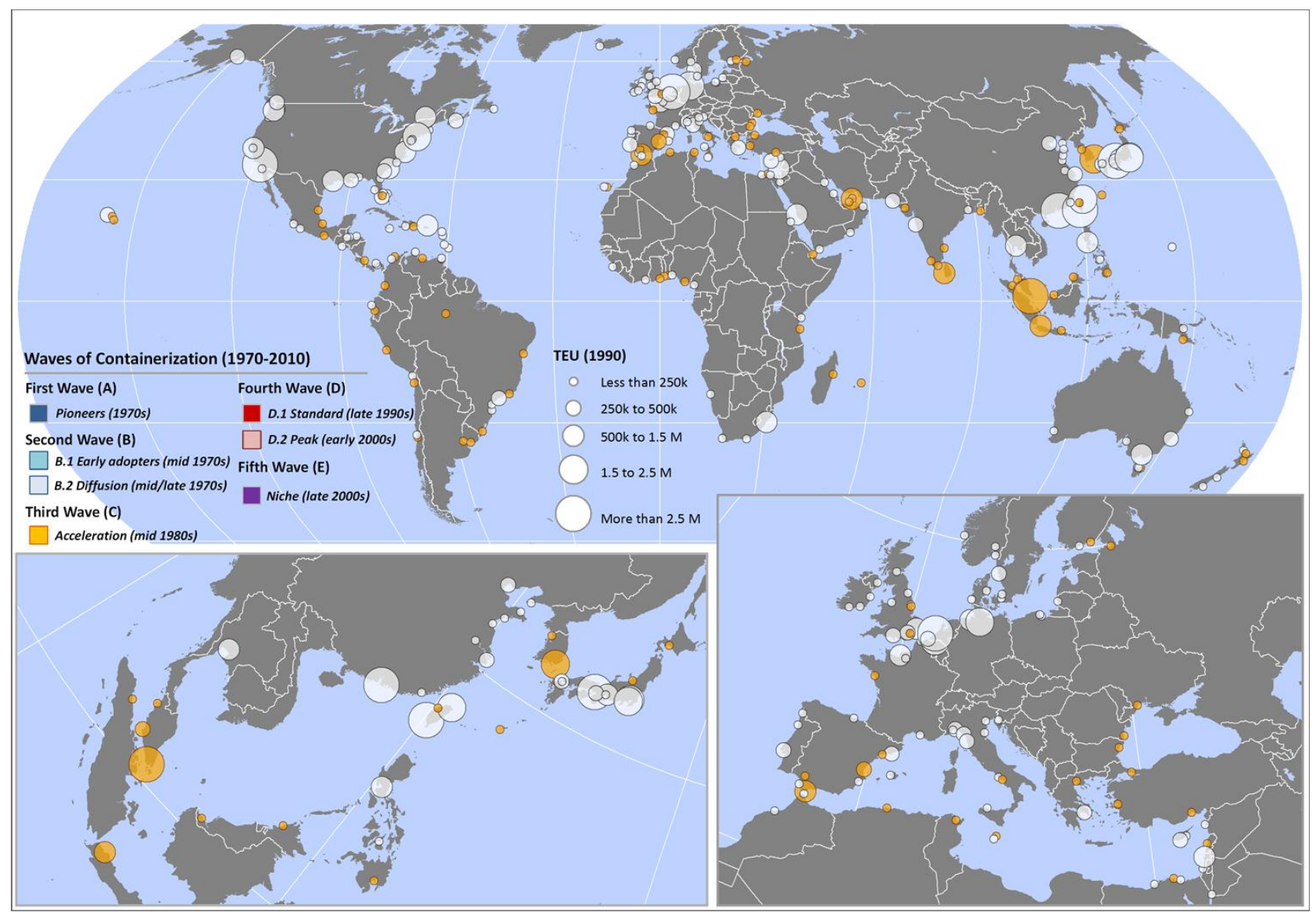

Figure 9 : The Third Wave of Containerization, 1990 - Global Diffusion

Fourth wave (D); global standard (Figure 10). Concerns two phases, D.1 and D.2, which are similar in their pattern and only different in their timing. From the mid-1990s, the container became the standard mean for global freight distribution, particularly with the massive entry of Chinese ports in global shipping networks (D.1) and the emergence of post-panamax ships. Several ports in this wave are new transshipment hubs been inserted to accommodate the growing network complexity and to better link regional ports to deep sea services (e.g. Salalah, Gioa Tauro, Colon, Freeport). New gateways are also emerging to accommodate growth in emerging economies (e.g. Vietnam, Mexico, India, Brazil). The later stage of that wave (D.2) concerns China gateway ports that provide additional export capabilities (some spillover effect) for massive manufacturing clusters (e.g. Ningbo, Guangzhou). For the rest of the world, they mostly concern additional transshipment hubs being set by global terminal operators (e.g. Tanjung Pelepas). 


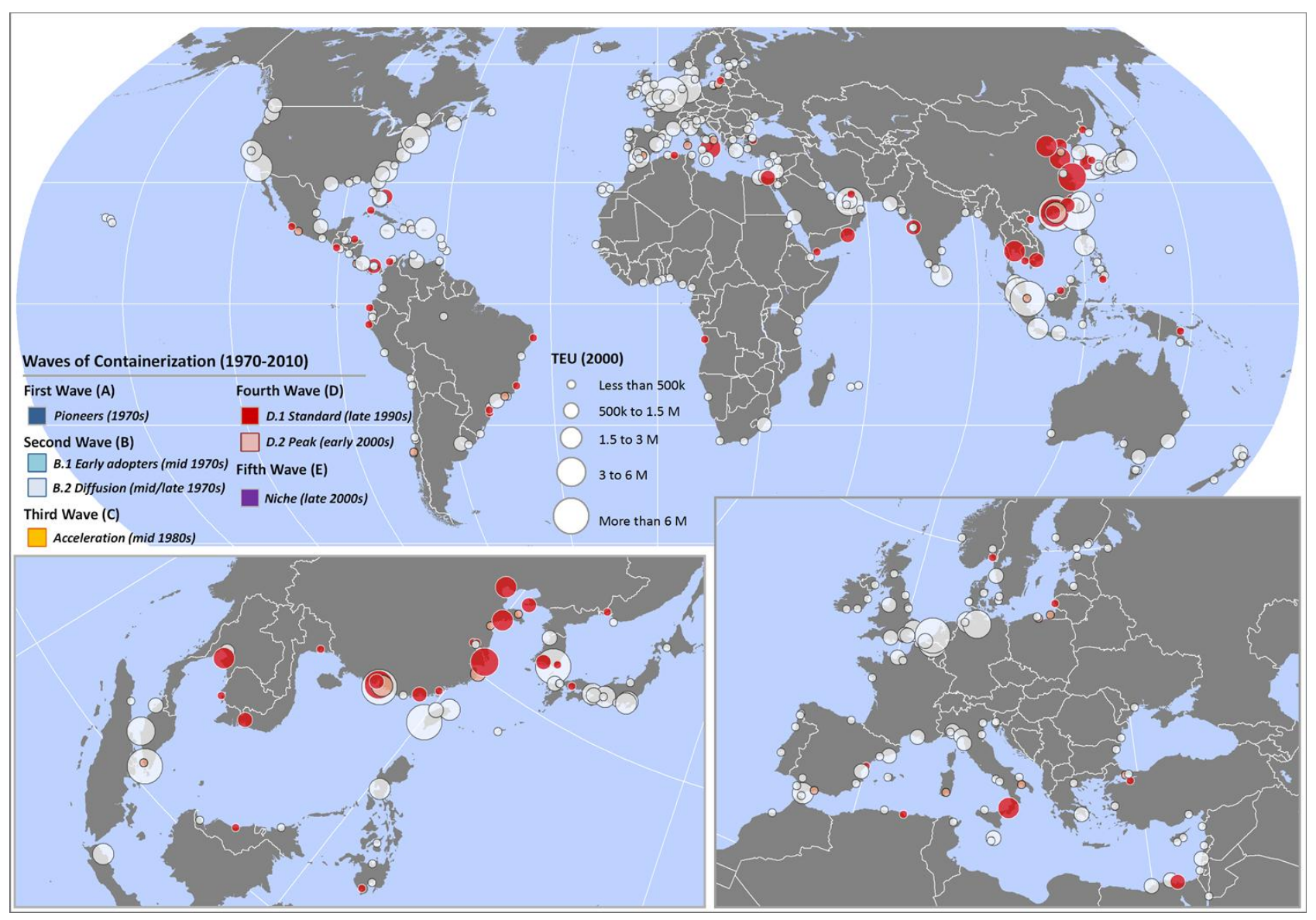

Figure 10 : The Fourth Wave of Containerization, 2000 - Global Standard

Fifth wave (E); peak growth (Figure 11). Concerns ports that have emerged recently (late 2000s) and is linked to peak growth in global container shipping. It is particularly one of niche ports filling as specific role, such as a new gateway to cope with congestion along a range (Yingkou or Taicang), or a new transshipment hub being inserted within maritime shipping networks (e.g. Tangier Med, Caucedo). Prince Rupert in Canada a typical example since it is the only port of significance that has emerged on the North American west coast in recent years, capitalizing on short transpacific transit times and a direct rail connection to the heartland (Chicago). 
The Waves of Containerization: Shifts in Glabal Maritime Transportation

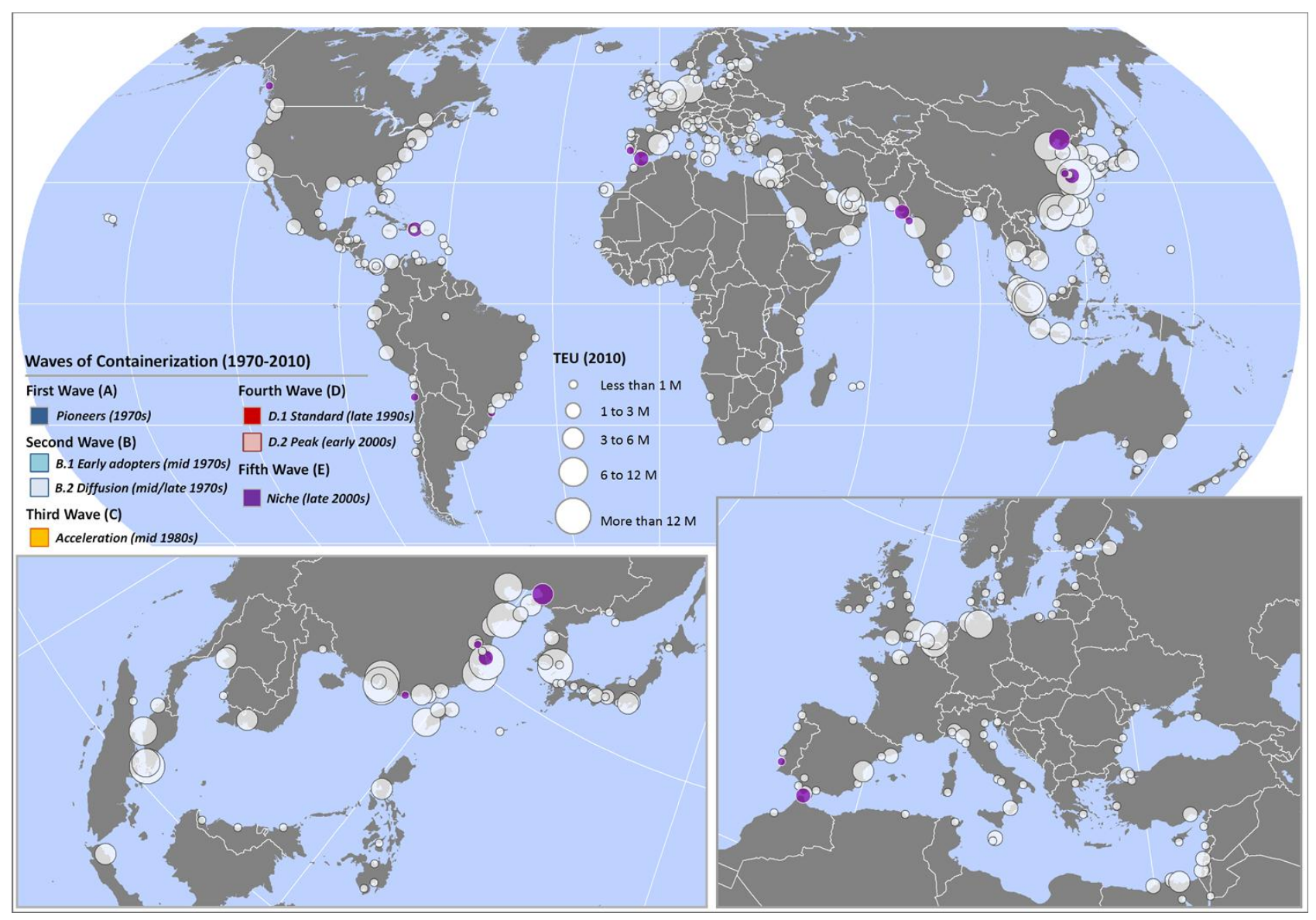

Figure 11 : The Fifth Wave of Containerization, 2010 - Peak Growth

The cumulative waves are depicted on Figure 12, which shows global traffic in 2010 and the wave (cluster class) each port belongs to. 
The Waves of Containerization: Shifts in Global Maritime Transportation

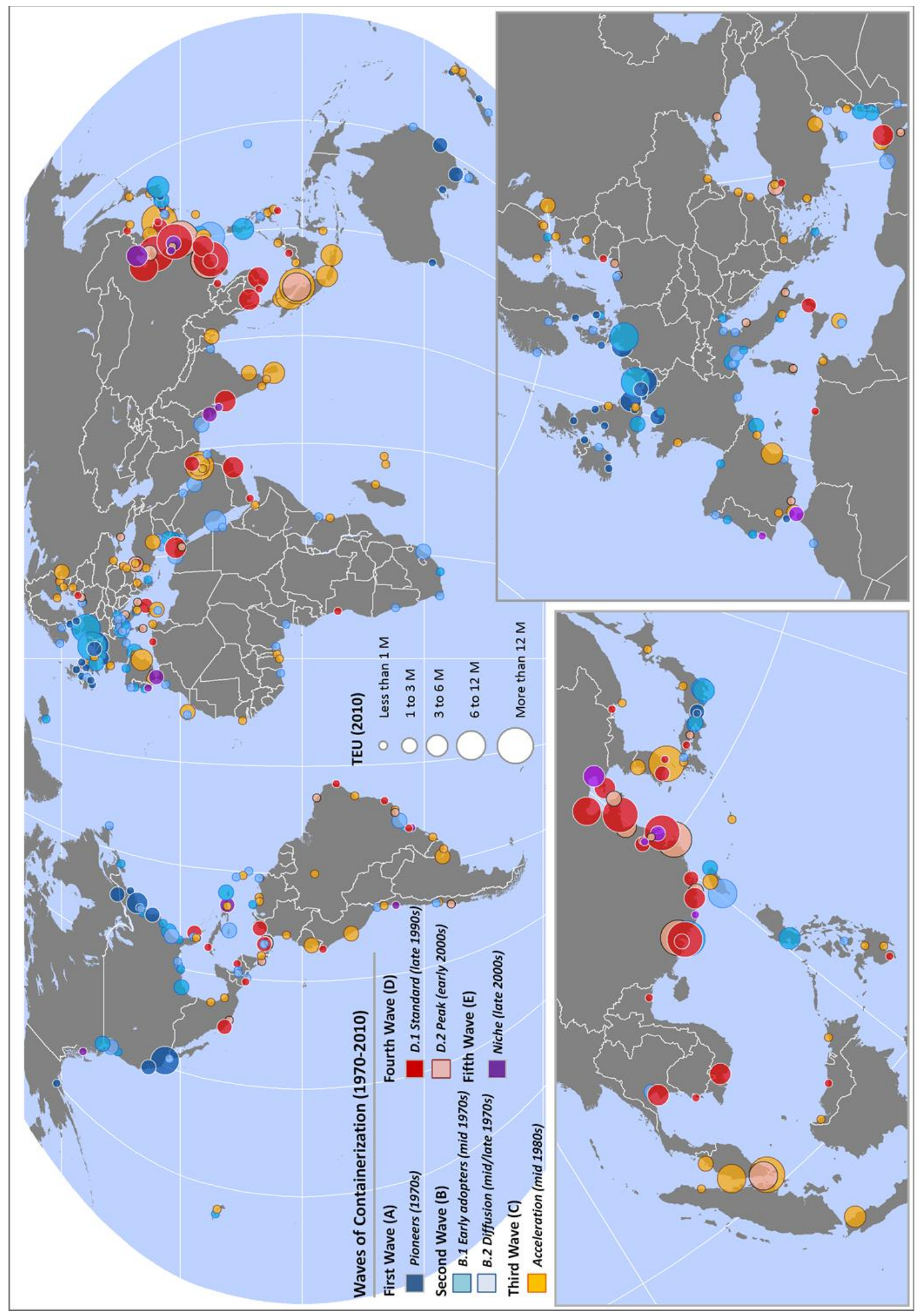

Figure 12 : Waves of Containerization, 1970-2010 
Table I: Long Waves of Containerization, 1970-2010

\begin{tabular}{|c|c|c|c|c|c|}
\hline & First Wave (A) & $\begin{array}{l}\text { Second Wave (B.1 \& } \\
\text { B.2) }\end{array}$ & Third Wave (C) & $\begin{array}{l}\text { Fourth Wave (D.1 } 8 \\
0.2)\end{array}$ & Fifth Wave (E) \\
\hline Periad & 1956 (1965) -1975 & $\begin{array}{l}\text { 1970-1980 (B.I) } \\
1975-1985 \text { (B.2) }\end{array}$ & $1980-1990$ & $\begin{array}{l}1995-(D .1) \\
2000-(D .2)\end{array}$ & $2005-$ \\
\hline Overview & $\begin{array}{l}\text { Pioneer ports setting } \\
\text { containerized } \\
\text { operations in the } \\
\text { economic triad (North } \\
\text { America, Western } \\
\text { Eurape and Japan). }\end{array}$ & $\begin{array}{l}\text { Expansion of the triad } \\
\text { and its trade partners } \\
\text { (Caribbean, } \\
\text { Mediterranean, Asian } \\
\text { Tigers). }\end{array}$ & $\begin{array}{l}\text { Large diffusion in new } \\
\text { markets (Latin } \\
\text { America, Middle East / } \\
\text { South Asia, Southeast } \\
\text { Asia). }\end{array}$ & $\begin{array}{l}\text { The container } \\
\text { becoming the } \\
\text { standard transport } \\
\text { support of the glabal } \\
\text { economy. "The China } \\
\text { Wave" }\end{array}$ & $\begin{array}{l}\text { Peak growth and the } \\
\text { setting of niches. }\end{array}$ \\
\hline Driver & $\begin{array}{l}\text { Early trade } \\
\text { substitution. }\end{array}$ & $\begin{array}{l}\text { Adoption of } \\
\text { containerization. }\end{array}$ & $\begin{array}{l}\text { Setting of global } \\
\text { supply chains. Setting } \\
\text { of transshipment } \\
\text { hubs. }\end{array}$ & $\begin{array}{l}\text { Expansion of glabal } \\
\text { supply chains. China } \\
\text { and transshipment } \\
\text { hubs. }\end{array}$ & $\begin{array}{l}\text { Spillover effect and } \\
\text { new transshipment } \\
\text { hubs. }\end{array}$ \\
\hline Representative ports & $\begin{array}{l}\text { Antwerp, New Yark, } \\
\text { Los Angeles, Cakland, } \\
\text { Nagaya }\end{array}$ & $\begin{array}{l}\text { B.I: Rotterdam, Tokya, } \\
\text { Hong Kang } \\
\text { B.Z: Kaohsiung, } \\
\text { Jeddah, Kingstan }\end{array}$ & $\begin{array}{l}\text { Singapore, Colombo, } \\
\text { Busan, Dubai, } \\
\text { Algeciras }\end{array}$ & $\begin{array}{l}\text { D.I Shanghai, } \\
\text { Shenzhen, Cioa Tauro } \\
\text { D.Z: Ningbo, Tanjung } \\
\text { Pelepas }\end{array}$ & $\begin{array}{l}\text { Tangier Med, Caucedo. } \\
\text { Yingkou, Prince } \\
\text { Rupert }\end{array}$ \\
\hline
\end{tabular}

The long wave analysis underlines that each wave lasts about 8 to 10 years, which is similar to the observations made by Kondratieff. The diffusion pattern is hierarchical, starting at the then absolute centers of the global economy (the triad) and adopting a pattern incorporating new locations within their respective spheres of influence. It is thus highly reflective of the change in the hierarchy of commercial relations that took place with globalization and containerization.

\section{MEDIUM WAVES OF CDNTAINERIZATIINN}

Shift-share analysis (SSA) has been extensively used in port studies to evaluate changes in the respective weight of ports along maritime ranges (e.g. Marti, 1982; Notteboom, 1997; Haezendonck, 2001). A simple version of shift-share analysis is applied, which focus solely on share-effect since container traffic is the only commodity being considered. SSA considers two periods, one acting as a reference and the other as the case to evaluate the difference from the reference period. If an observation has the same share of the total traffic in the case period compared with the reference period, than its shift share is close to zero. A negative shift-share implies that an observation has less traffic than expected (if its share remained constant), while a positive shift-share implies the opposite. The analysis is very useful to evaluate the level of divergence from a reference distribution and to identify observations that are standing out.

The selection of the time frame for the shift-share analysis relates to the $2000-2010$ period, which on Figure 5 represents a critical juncture as the share of waves A, B and C was waning while wave D was fully asserting itself and wave E would be felt from 2005 onward. Containerization entered the exponential inflection point with total traffic in the sample 
growing by a factor of 2.32 times over the decade (from 223 to 518 million TEUs), exceeding the combined absolute growth of all the previous decades.

As for the previous analysis, the dataset is coming from Containerization International, but this time it concerns annual port traffic from 2000 to 2010. Ports that had more than 2 missing yearly observations were removed from the analysis; a total of 264 ports were retained. 14 missing observations out of 2,904 (264 x 11) observations were estimated through linear interpolation using two adjacent years.

The shift-share analysis was divided over two periods, 2000-05 and 2005-10, and therefore was able to look at two medium waves that unfolded during the 2000 s and marked a paradigm shift in containerization. The first period captures the fast growth where container ports in developing economies were incorporated in the global trade system (Figure 13), while the second period captures the impacts of the financial crisis of 2008-09 on a global container transport system that was until then experiencing full-fledged and almost uninterrupted growth (Figure 14). It is important to underline that the results of the SSA must be interpreted in the global context of the container port system and not within respective regions (or port range).

A look at the ports that have experienced the highest gain and decline in share during the period is revealing as both the ports with the highest gain and decline are dominantly in Asia (Table 2). This underlines a growing divergence in regional containerization dynamics. The case of Hong Kong is eloquent since the port dominated the Pearl River Delta, but in the 2000s it became the world's major port that has lost the most significant share of its traffic even as this traffic increased from 18.1 million TEU in 2000 to 23.7 million TEU in 2010. This underlines capacity limitations challenges in its ability to service its hinterland in light of the substantial growth of other ports in the Pearl River Delta (Shenzhen and Guangzhou).

Table 2 : Shift-Share Analysis, Ports with the Highest Gain and Decline, 2000-05 and 2005-10

\begin{tabular}{|c|c|c|}
\hline & 2000-05 & $2005-10$ \\
\hline Highest gain & $\begin{array}{l}\text { Shenzhen (+25.54) } \\
\text { Shanghai (+23.21) } \\
\text { Ningbo (+9.95) } \\
\text { Tanjung Pelepas (+9.89) } \\
\text { Cingdan (+7.35) } \\
\text { Dubai (+6.60) }\end{array}$ & $\begin{array}{l}\text { Guangzhou (+12.57) } \\
\text { Ningbu (+12.34) } \\
\text { Shanghai (+9.54) } \\
\text { Tianjin (+7.28) } \\
\text { Qingdan (+7.09) } \\
\text { Lianyungang (+5.07) }\end{array}$ \\
\hline Highest decline & $\begin{array}{l}\text { Hong Kang (-22.15) } \\
\text { Singapare (-15.34) } \\
\text { Kaohsiung (-8.42) } \\
\text { Manila (-6.05) } \\
\text { Felixstawe (-5.50) } \\
\text { Kabe (-4.26) }\end{array}$ & $\begin{array}{l}\text { Hong Kong (-13.18) } \\
\text { Kaohsiung (-7.16) } \\
\text { Busan (-6.02) } \\
\text { Hamburg (-5.99) } \\
\text { Singapore (-5.61) } \\
\text { Long Beach (-5.56) }\end{array}$ \\
\hline
\end{tabular}




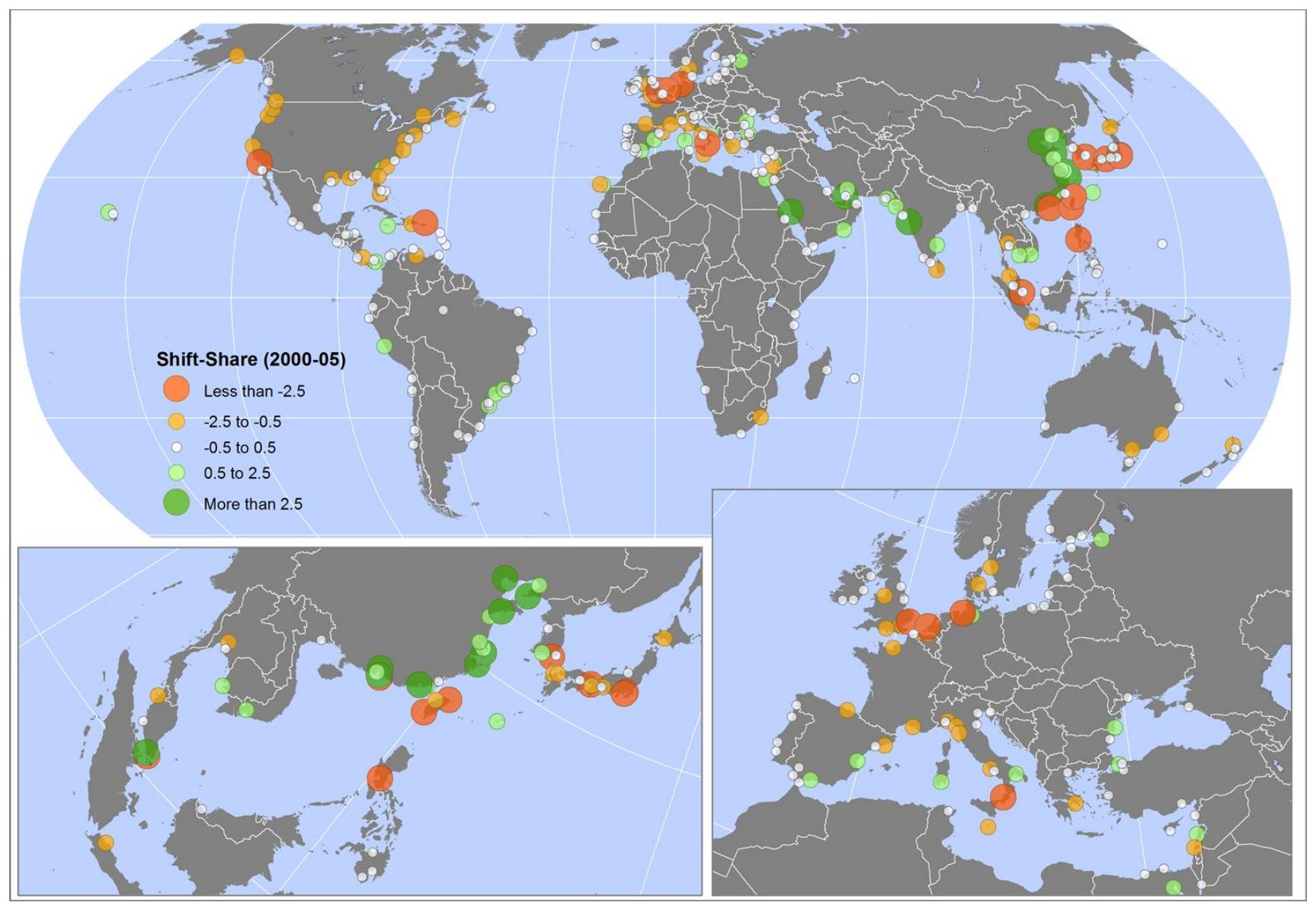

Figure 13 : Shift-Share Analysis, World Container Ports, 2000-05

Although many interpretations of the shift-share can be made at the individual port level, the following general trends that can be observed. A complete shift in the growth dynamics of global container ports has taken place where the triad shows signs of maturity and its related shift-share decline. Within Pacific Asia, a rapid shift from Jakota (Japan, Korean and Taiwan) to mainland China took place in a fashion which is almost symmetric. The strengthening and some rebalancing of transshipment hubs along the Singapore - Gibraltar corridor is being noted. Dubai is one of the main port gaining, a process concomitant to the emergence of Dubai Ports World as a major global terminal operator and the growing role of Dubai as a transshipment hub. A maturity within the North American and Northern European ranges is taking place with an across the board drop in the share of containerized traffic. A rebalancing of transshipment hubs is being observed within the Mediterranean and the Caribbean towards hubs offering higher levels of efficiency, with Valencia and Algeciras gaining. 


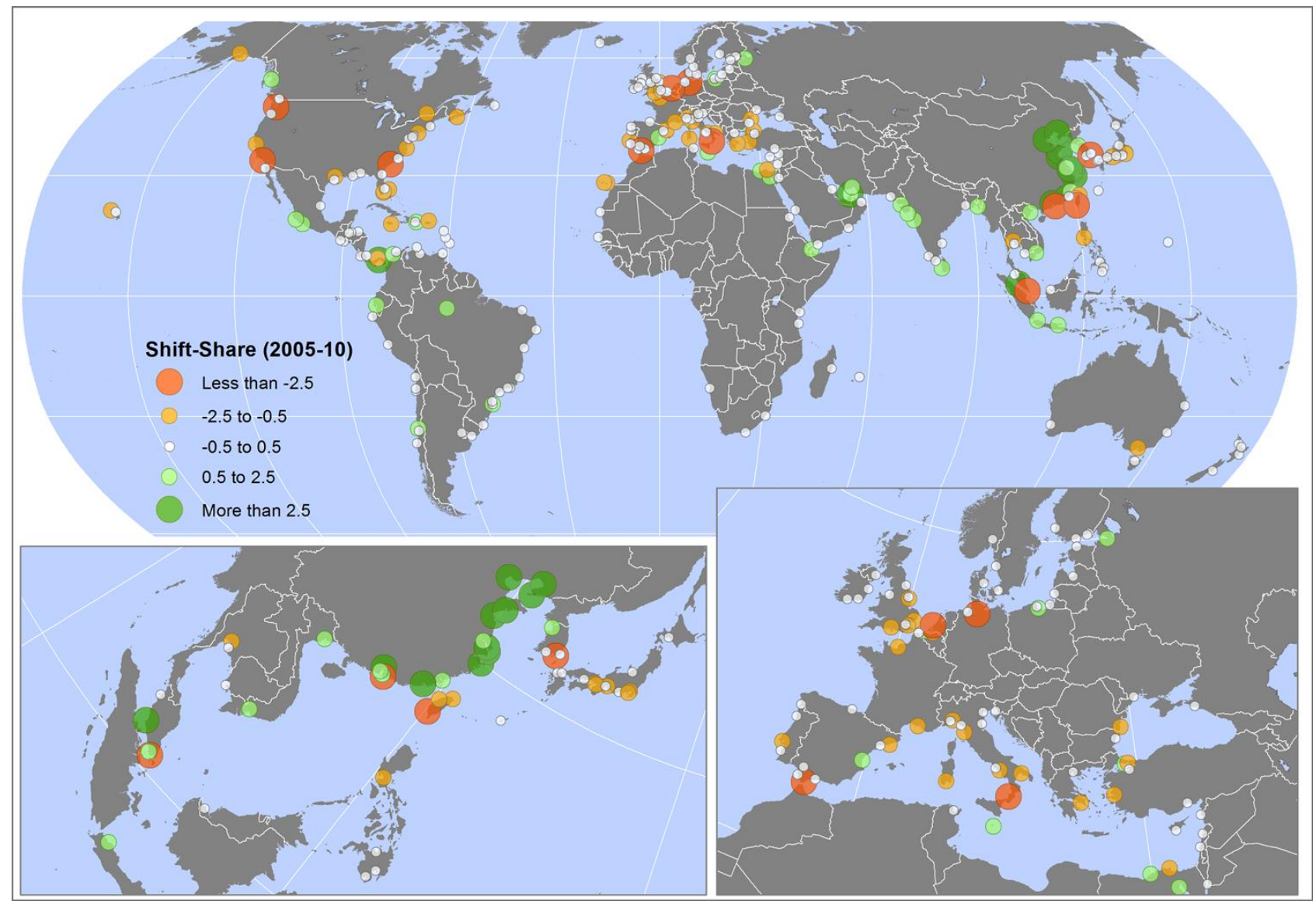

Figure 14 : Shift-Share Analysis, World Container Ports, 2005-10

Although the financial crisis of 2008-09 was characterized by a significant decline of global container throughput, this decline was far from being uniform. The medium wave unfolding from 2005, therefore, includes both growth and rationalization processes. The ongoing relative decline of Singapore and Hong Kong within their respective regional setting is being noted on par with the continuation of containerization along coastal China as its exportoriented development model peaked. There is an ongoing strengthening of transshipment hubs along the Singapore - Suez corridor, with Dubai continuing to dominate. At the same time, a rationalization of transshipment in the Mediterranean to the main advantage of Valencia and Tangier Med is taking place. The steep decline of the share of North American ports is marginally counterbalanced by the strengthening of niche gateways (Lazaro Cardenas, Savannah, Prince Rupert) and an ongoing rebalancing of transshipment in the Caribbean to the advantage of Panama and Cartagena. There is an overall gain of South American ports linked to ongoing economic growth, their integration to the global economy, particularly to the transpacific trade.

\section{SHORT WAVES OF CONTAINERIZATIINN}

Monthly port traffic data is more challenging to come by as some ports will post current figures on their web sites while for others this information will not be made available because of competition concerns. Data from 2005 to 2011 was compiled for eight ports and 
normalized to facilitate comparison (Figure 15). In all cases, the financial crisis of 2008-2009 marks a distinctive break in the pattern.
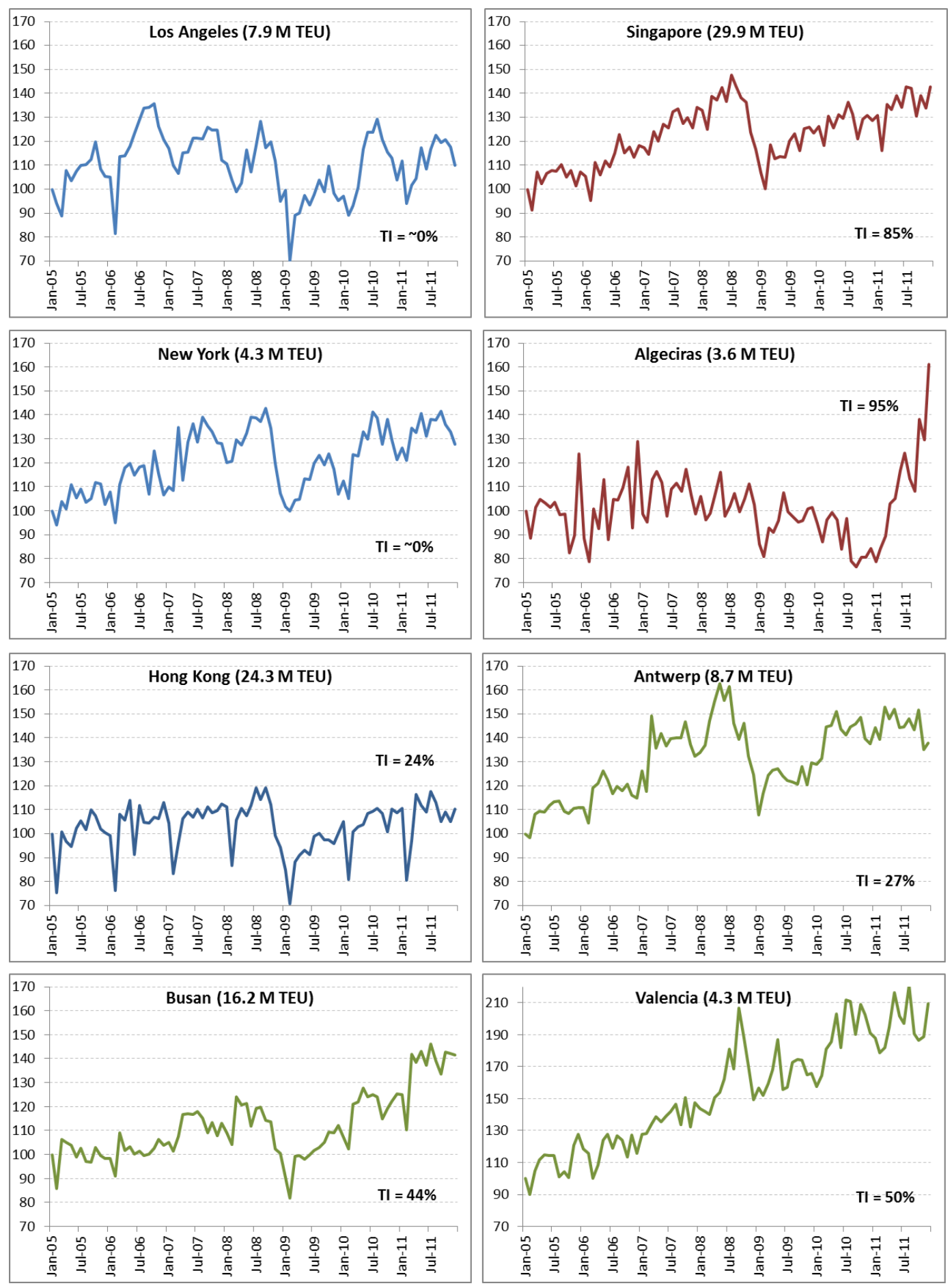

Figure 15 : Monthly Container Traffic, Selected Ports, 2005-2011 (Jan 2005 =100)

${ }^{1}$ Source: Port Authorities. Note: TI = transshipment incidence. Blue = gateway ports; Red $=$ transshipment hubs; Green = hybrid ports. 
Three distinct categories emerge when looking at monthly container traffic as gateway ports and transshipment hubs depict different dynamics. Gateway ports (Los Angeles, New York and Hong Kong in this sample) have a notable annual variation in amplitude with peak periods generally corresponding to the late summer and early fall and through periods corresponding to mid-winter (January and February). This is linked with annual retail cycles where sales pick up during November and December and immediately drop afterwards. For instance, the holiday season in the United States accounts for many major retailers between 25 and $50 \%$ of annual sales ${ }^{2}$. Such a consumption pattern is therefore reflected in gateway port traffic fluctuations. The financial crisis of 2008-09 did not impact on the pattern, but simply on the amplitude of the drop in traffic at the end of 2008 and early 2009.

The second category concerns pure transshipment hubs (Singapore and Algeciras with a transshipment incidence of more than $85 \%$ ) that do not readily show a recognizable pattern of annual traffic fluctuation and tend to have lower amplitude. This implies that transshipment hubs appear to have a more stable traffic structure than gateway ports, but this stability is pondered against the risk of having maritime shipping companies switch their traffic if their service network configuration changes. In this case, the shift in traffic patterns can be dramatic. For instance, the monthly traffic of the port of Algeciras surged in 2011, the outcome of a decision by Maersk to shift a part of its transshipment activities from Tangier Med (Morocco), which is just on the other side of the Strait of Gibraltar.

The third category represents hybrid ports that have a transshipment incidence between 25 and 50\% (Antwerp, Busan and Valencia). They show a pattern of traffic fluctuation with a through period (January) like gateway ports, but this pattern is less distinctive, particularly as the transshipment incidence increases (Valencia). For several transshipment hubs and hybrids ports the financial crisis marked a break in their growth pattern, but little changes in their amplitude.

Figure 16 illustrates the aggregated monthly traffic patterns for the eight sample ports from 2005 to 2011. The comparison of the average pattern (2005-2011) with those of 2009 and 2010 demonstrates that financial crisis had little discernable effect on the yearly seasonal traffic distribution. In the specific case of the port of Los Angeles, flat activity levels were experienced in the recession year of 2009 between May and September, then a recovery in 2010. This could be related with companies ordering goods ahead of the Christmas season, though they waited until the last minute because they were not yet convinced that the consumer demand would materialize. Since the global container transport system was in a situation of chronic overcapacity, retailer felt confident that their delayed orders would still be available on main consumption markets.

\footnotetext{
${ }^{2}$ National Retail Association, http://www.nrf.com
} 

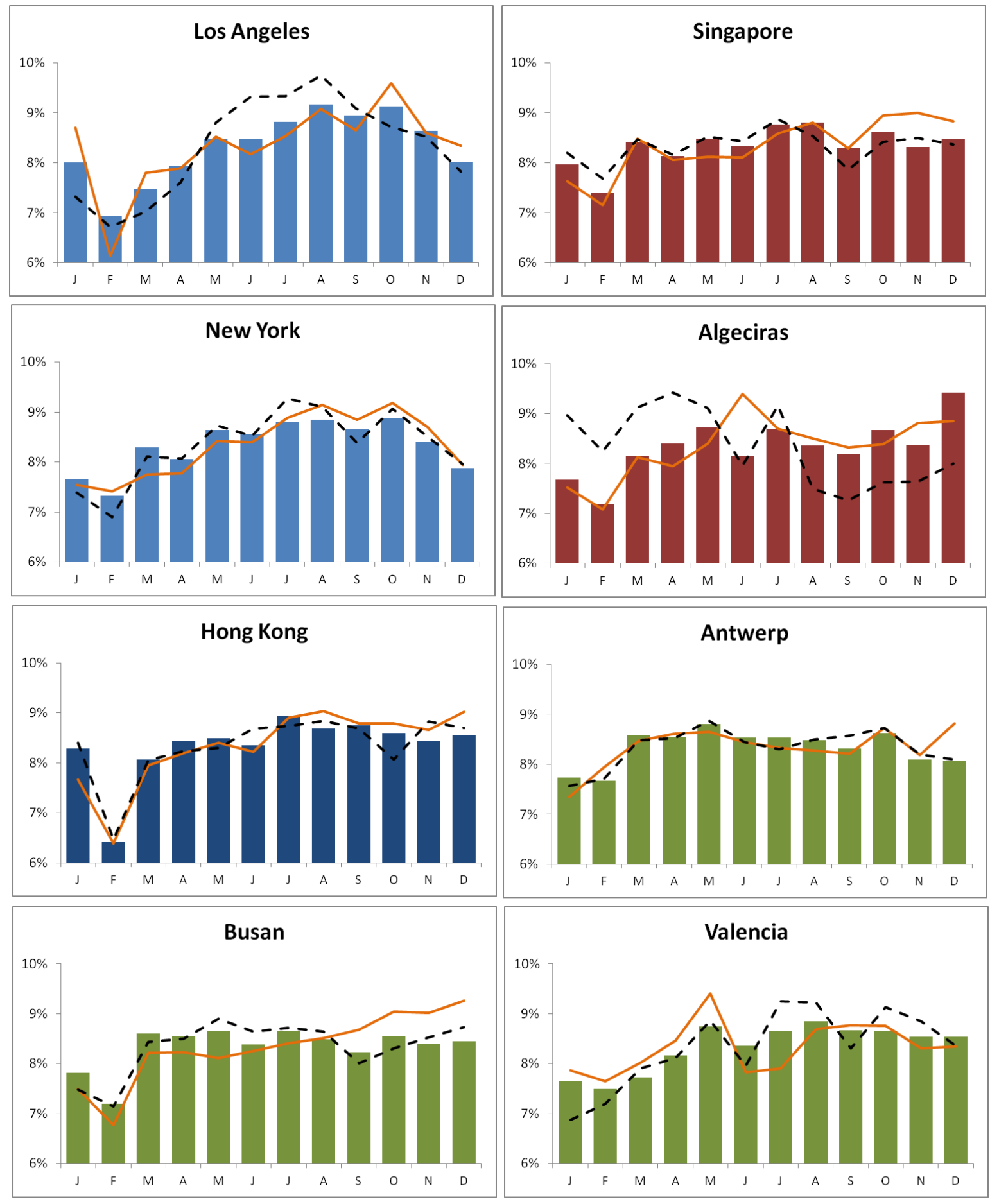

Average Monthly share 2005-2011

2009 Monthly share

2010 Monthly share

Figure I6 : Average Monthly Lontainer Traffic Share, Selected Ports, 2005-2011

${ }^{3}$ Source: Port Authorities. Note: Blue = gateway ports; Red = transshipment hubs; Green = hybrid ports. 


\section{CDNCLUSIDN}

This paper provided evidence of the cyclic behavior of containerization through an analysis of long, medium and short waves of container ports. The container, like any technical innovation, has a market and diffusion potential where a phase of maturity is eventually reached. Evidence from the global container port system suggests five major successive long waves of containerization with a shift of the momentum from advanced economies to developing economies, but also within advanced and developing economies. Long waves show a distinct pattern that is highly reflective of the process of economic globalization from the initial dominance of the triad to the incorporation of export-oriented economies in the global trade system and the emergence of major transshipment hubs. These long waves span about 8 to 10 years each, which matches the patterns initially identified by the work of Kondratieff.

Medium waves, particularly in light of the impacts of the financial crisis of 2008-09, are illustrative of an inflexion and a shift in the patterns of global container port growth. The tendencies depicted by a shift-share analysis have shown that the core growth has focused mainly to coastal Chinese ports as well as for emerging transshipment hubs along the AsiaMediterranean trade route. South Asia and Latin America have also fared comparatively well. It shows that in the same region ports like Shanghai, Shenzhen and Ningbo are achieving peak growth while ports like Hong Kong, Singapore and Kaohsiung have achieved maturity. This is illustrative of the economic and manufacturing rebalancing that has taken place in the last decade.

Short waves are generally not associated with growth patterns taking place within long and medium waves and are thus expressing a distinct functional behavior. They are reflective of the seasonality of the hinterland serviced by a container port as well as the balance of gateway and transshipment functions. Ports having a pronounced import retail function have clear and distinctive short waves while transshipment hubs are characterized by a much less distinct seasonality.

While long, medium and short wave patterns have been clearly identified within the global container port system, these waves are simply illustrative of major macroeconomic, technological and sometimes political shifts within the global economy. They do not explain the causes, but simply the consequences of such shifts in the distribution in traffic and growth (or decline). Yet, they provide strong evidence that containerization has a cyclic behavior and that inflection points are eventually reached, marking the end of the diffusion of containerization in a specific port or port range. Future expectations about the growth of containerization thus need to be assessed within an economic cycle perspective instead of the rather linear perspectives in which containerization is generally considered. This paper focused on the port level. It would be revealing if more detailed analysis could be performed at the port range level as well as if cycles can be observed within the configuration of shipping networks.

\section{REFERENCES}

Bird, J.H (1963) The major seaports of the United Kingdom, London: Hutchison.

Ducruet C. and F. Zaidi (2012) "Maritime constellations: a complex network approach to shipping and ports", Maritime Policy and Management, Vol. 39, No. 2, pp. 151-168. 
Everitt, B. S., S. Landau, and M. Leese (2001) Cluster Analysis, 4th Edition, New York: Oxford University Press.

Fremont, A. (2007) “Global maritime networks: The case of Maersk”, Journal of Transport Geography, Vol. 15, pp. 431-442.

Haezendonck, E. (2001) Essays on Strategy Analysis for Seaports, Garant: Leuven.

Hayes, R.H. and S.C. Wheelwright (1979) "Link manufacturing process and product life cycles”, Harvard Business Review, Vol. 57, No. 1, pp. 133-140.

Hayuth, Y. (1981) "Containerization and the load center concept”, Economic Geography, 57(2), pp. 160-176.

Kuczynski, T. (1980) "Have there been Differences between Growth Rates in Different Periods of the Development of the Capitalist World Economy since 1850? An Application of Cluster Analysis in Time Series Analysis" in J.M. Clubb and E.K. Scheuch (eds.) Historical Social Research, Vol. 6, pp. 300-316, Stuttgart: Kett-Gotta.

Kondratieff, N.D. (1935) "The Long Waves in Economic Life", The Review of Economic Statistics, Vol. 17, No. 6, pp. 105-115.

Levinson, M. (2006) The Box: How the Shipping Container Made the World Smaller and the World Economy Bigger, Princeton: Princeton University Press.

Marti, B.E. (1982) "Shift-share analysis and port geography: a New England example”, Maritime Policy \& Management, Vol. 9, No. 4, pp. 241-250.

Notteboom, T. (2007) "Spatial dynamics in the container load centres of the Le Havre-Hamburg Range”, Zeitschrift für Wirtschaftsgeographie, Vol. 51, No. 2, pp. 108-123.

Notteboom, T. (2006) "Traffic Inequality in Seaport Systems Revisited", Journal of Transport Geography, Vol. 14, No. 2, pp. 95-108.

Notteboom, T. and J-P Rodrigue (2009) "The Future of Containerization: Perspectives from Maritime and Inland Freight Distribution", Geojournal, Vol. 74, No. 1, pp. 7-22.

O'Connor, K. (2010) "Global City Regions and the Location of Logistics Activity", Journal of Transport Geography, Vol. 18, No. 3, pp. 354-362.

Rodrigue, J-P, C. Comtois and B. Slack (1997) "Transportation and Spatial Cycles: Evidence from Maritime Systems", Journal of Transport Geography, Vol. 5, No. 2, pp. 87-98.

Rodrigue, J-P and T. Notteboom (2009) "The Terminalization of Supply Chains: Reassessing the Role of Terminals in Port / Hinterland Logistical Relationships" Maritime Policy and Management 36 (2), pp. $165-183$.

Slack, B. (1999) "Across the Pond: Container Shipping on the North Atlantic in the Era of Globalisation", Geojournal, Vol. 48, No. 1, pp. 9-14,

Talley, W.K. (2000) "Ocean Container Shipping: Impacts of a Technological Improvement", Journal of Economic Issues, Vol. 34, No. 4, pp. 933-948.

Tongzon, J.L. (1995) “Systematizing international benchmarking for ports”, Maritime Policy \& Management, Vol. 22, No. 2, pp. 171-177. 